\title{
The influence of curing and aging on chloride transport through ternary blended cement concrete
}

\author{
F. J. Luna, Á. Fernández, M. C. Alonso凶 \\ Department of Construction, Instituto de Ciencias de la Construcción Eduardo Torroja-Consejo Superior de Investigaciones \\ Científicas, C/Serrano Galvache, 428033 Madrid (España) \\ \mcalonso@ietcc.csic.es \\ Received 8 November 2017 \\ Accepted 4 April 2018 \\ On line first 03 September 2018
}

\begin{abstract}
The effect of the extension of the curing period and exposure time to a chloride source on the transport of these ions has been studied in concrete with 100\% Portland cement (OPC) and with ternary cement composed of $64 \%$ OPC, 30\% blast furnace slag (BFS) and 6\% limestone filler (LF). The extension of the curing time (from 28 to 90 days) did not significantly affect the transport, even in concretes with supplementary cementitious materials (SCM's). The exposure time to the chloride source (3,6 and 12 months) is a parameter which had a major influence on the transport. At least 6 months of exposure were necessary to achieve stable chloride diffusion coefficients with more noticeable stabilization occurring when SCM's were used. The presence of BFS significantly decreased the transport, due to its ability to combine chloride rather than the refinement of capillary pores as a consequence of its late hydration.
\end{abstract}

KEYWORDS: Concrete; Blast furnace slag; Chloride; Curing; Diffusion.

Citation/Citar como: Luna, F.J.; Fernández, Á.; Alonso, M.C. (2018). The influence of curing and aging on chloride transport through ternary blended cement concrete. Mater. Construcc. 68 [332], e171 https://doi.org/10.3989/ mc.2018.11917

RESUMEN : Influencia del tiempo de curado y envejecimiento en el transporte de cloruros a través de hormigones con cementos de mezclas ternarias. Se estudia el efecto de la extensión del tiempo de curado y exposición a una fuente con cloruros en el transporte de dichos iones a través de hormigones con $100 \%$ de cemento Portland (OPC) y con cemento ternario compuesto por $64 \%$ OPC, $30 \%$ escorias de alto horno (BFS) y $6 \%$ fíller calizo (LF). La extensión del tiempo de curado (de 28 a 90 días) no afecta significativamente al transporte de cloruros, incluso en hormigones con adiciones minerales. El tiempo de exposición a los cloruros (3, 6 y 12 meses) es un parámetro muy influyente en el transporte, siendo al menos 6 meses necesarios para llegar a coeficientes de difusión estables, con un efecto del tiempo de exposición más crítico en hormigones con adiciones minerales. Las BFS disminuyen significativamente el transporte más por su capacidad de combinar cloruro que por el refinamiento en poros capilares por su hidratación tardía.

PALABRAS CLAVE: Hormigón; Escorias granuladas de alto horno; Cloruros; Curado; Difusión.

ORCID ID: F. J. Luna (http://orcid.org/0000-0002-5236-694X); Á. Fernández (http://orcid.org/0000-0002-0793-969X); M.C. Alonso (http://orcid.org/0000-0002-4308-9506)

Copyright: (C) 2018 CSIC. This is an open-access article distributed under the terms of the Creative Commons Attribution 4.0 International (CC BY 4.0) License 


\section{INTRODUCTION}

When a reinforced concrete structure is located in a chloride-contaminated environment, the chloride ions penetrate into the concrete, moving towards the reinforcement, which favors the initiation and propagation of corrosion (1). The final consequence of the progressive accumulation of chlorides at the rebar level on the structural performance is the damage of the rebars and the structures, i.e. the progressive cracking of the concrete cover, the loss of the steel cross-section, and the decrease in the concrete/ rebar bond.

The end of the service life of a reinforced concrete structure is usually associated with the durability limit state of corrosion initiation, avoiding corrosion propagation (2-4). Different strategies can be followed to delay the arrival of chlorides at the reinforcement level, i.e. to extend the transport period. The increase in the thickness of the concrete cover, according to the aggressiveness of the environment, as prescribed by some structural concrete standards (5) is one way to deal with the extension of time that the chlorides take to reach the rebar level. Another method for extending the period of chloride penetration into concrete is to modify the cementitious matrix (6).

The type of cement, with regard to the incorporation of supplementary cementitious materials (SCM's), has been revealed to be among the factors which have the greatest influence on the resistance of concrete to chloride penetration (7-14). Blast furnace slag (BFS) is one of the most commonly used SCM's in the manufacture of concretes which are intended for exposure to chloride-contaminated environments, especially marine ones (15), due to its ability to retard the entrance of chloride $(16,17)$.

The slower penetration of chlorides into concretes containing BFS in comparison to Portland cement concretes is associated with two different phenomena. The hydration of BFS favors the formation of additional C-S-H gel with a similar structure to that of ordinary Portland cement (OPC) which contributes to making the system denser, but with a lower $\mathrm{CaO} / \mathrm{SiO}_{2}$ ratio (18-25). Al is also incorporated into the C-S-H to a greater extent (19-21). All of the above changes in the microstructure of cement paste with BFS contribute to the decrease in the penetration rate of chlorides into the concretes containing this SCM. Furthermore, the inclusion of BFS in cement leads to concretes with more refined pore structures (26) and lower water permeability (27) that can contribute to making the transport of chlorides through these matrixes more difficult, therefore extending the transport period.

The above mentioned results have mainly been deduced from experiments on cementitious matrixes manufactured with binary binders made of Portland clinker and BFS $(9,16,17)$. However, little knowledge on ternary cements containing ordinary Portland cement (OPC), BFS and other SCM's exists (28).
It is also well-known that the hydration period of BFS cement concretes is slower than the hydration of OPC concretes (29). In fact, many studies have been carried out to discover the strength development of BFS cement concretes when the curing period is extended $(27,29,30)$. However, less attention has been paid to the effect of the slower hydration caused by BFS on the chloride penetration into cementitious matrixes $(31,32)$.

Beyond the effect of curing on chloride transport through concrete, work also exists which affirms that chloride diffusion coefficients vary with the exposure time to a chloride source $(33,34)$, a phenomenon known as aging, but again there is a lack of research on the effect of aging on chloride penetration into BFS cement concretes $(35,36)$.

In addition to the above, a notable part of the studies on chloride penetration has been carried out through tests promoting accelerated transport of chlorides $(37,38)$ and not through natural penetration (39), which is similar to field situations. Furthermore, the repeatability in the chloride transport processes and the number of specimens tested is not frequently considered in studies.

This research deals with the resistance to the penetration of chlorides through the natural diffusion of two concretes, plain Portland cement concrete and concrete containing a ternary binder composed of OPC, BFS and limestone filler (LF). This focuses on the evaluation of the effect of the extension of the curing period and the exposure time to the chloride sources. Furthermore, the variability of the chloride transport process has been analyzed.

\section{EXPERIMENTAL PROGRAM}

\subsection{Preparation of samples}

For transport studies, two types of concretes with different binder types were manufactured. One binder was $100 \%$ CEM I 42.5 R-SR 5, sulfate resistant with a low content of aluminates and an extremely low chloride binding capacity. The other binder was a ternary mix prepared in the laboratory with CEM I 42.5 R-SR 5 (64\%), BFS (30\%) and LF $(6 \%)$, to enhance the chloride binding capacity of the binder with the BFS addition. Table 1 shows the chemical compositions of CEM I 42.5 R-SR 5, BFS and LF.

The concrete containing 100\% CEM I 42.5 R-SR 5 has been named as OPC concrete and the concrete containing BFS and LF as SL concrete. Rounded siliceous aggregates from two fractions (0-4 and 4-12 $\mathrm{mm})$ were used. The amounts of the binder and the aggregates were kept constant for both concretes and water was added to reach similar slumps, 6.5 and $7 \mathrm{~cm}$ in OPC and SL concrete, respectively. The compositions of the concretes are shown in Table 2. 
TABLE 1. Chemical composition of CEM I 42.5 R-SR 5, BFS and LF ( $\%$ by weight)

\begin{tabular}{lcccccccc}
\hline \multicolumn{1}{c}{$\%$} & $\mathbf{N a}_{\mathbf{2}} \mathbf{O}$ & $\mathbf{K}_{\mathbf{2}} \mathbf{O}$ & $\mathbf{A l}_{\mathbf{2}} \mathbf{O}_{\mathbf{3}}$ & $\mathbf{C a O}$ & $\mathbf{F e}_{\mathbf{2}} \mathbf{O}_{\mathbf{3}}$ & $\mathbf{S i O}_{\mathbf{2}}$ & $\mathbf{M g O}$ & $\mathbf{S O}_{\mathbf{3}}$ \\
\hline CEM I 42,5 R-SR 5 & 0.18 & 0.34 & 4.68 & 60.30 & 5.08 & 17.40 & 1.78 & 3.17 \\
BFS & 0.42 & 0.49 & 10.39 & 45.50 & 0.29 & 36.57 & 7.46 & 0.05 \\
LF & 0.55 & 2.65 & 7.75 & 26.09 & 2.57 & 21.39 & 5.80 & 0.05 \\
\hline
\end{tabular}

TABLE 2. Compositions of the concretes

\begin{tabular}{lcccccc}
\hline Concrete & $\begin{array}{c}\text { Fine aggregate } \mathbf{0 / 6} \mathbf{~ m m} \\
\left(\mathbf{k g} / \mathbf{m}^{3}\right)\end{array}$ & $\begin{array}{c}\text { Coarse aggregate 6/12 } \mathbf{~ m m} \\
\left(\mathbf{k g} / \mathbf{m}^{3}\right)\end{array}$ & $\begin{array}{c}\text { CEM I 42,5 R/SR } \\
\left(\mathbf{k g} / \mathbf{m}^{3}\right)\end{array}$ & $\mathbf{B F S}\left(\mathbf{k g} / \mathbf{m}^{3}\right)$ & $\mathbf{~ L F ~}\left(\mathbf{k g} / \mathbf{m}^{3}\right)$ & $\mathbf{w / b}$ \\
\hline OPC & 802 & 842 & 385 & - & - & 0.6 \\
SL & 802 & 842 & 247 & 116 & 23 & 0.6 \\
\hline
\end{tabular}

Cubic specimens of concrete with $10 \mathrm{~cm}$ sides were manufactured. The effect of hydration was dealt with by imposing curing periods of 28 and 90 days. The specimens were cured in a chamber at $20 \pm 2^{\circ} \mathrm{C}$ and with a relative humidity of higher than $95 \%$ as prescribed in $(40)$.

For the characterization of the mechanical properties and the porous structure, mortars were used. Prisms of $4 \times 4 \times 16 \mathrm{~cm}$ in size with a water/binder $(\mathrm{w} / \mathrm{b})$ ratio of 0.5 and a binder:sand (b:s) ratio of $1: 3$ were manufactured as in (41), and used for the mechanical tests. For the porosimetry tests, samples of approximately $1 \times 1 \times 1 \mathrm{~cm}$ were extracted from the center of mortar prisms which had not been previously tested mechanically. As for the chloride transport tests, curing periods of 28 and 90 days and the same curing conditions were applied.

\subsection{Chloride penetration tests}

Preconditioning of specimens: At the end of the corresponding curing period, the specimens were vacuum saturated with water in accordance with the method prescribed in (42). In order to achieve this, the specimens were placed in the vacuum container and the absolute pressure was reduced to $1 \mathrm{kPa}$ for 3 hours. Then the container was filled with demineralized water until the specimens were immersed and the absolute pressure of $1 \mathrm{kPa}$ was maintained for a further hour, allowing air to re-enter the container.

Surface sealing and exposure to chlorides: After the vacuum saturation process, the standards prescribed in (42) were also followed to limit the side and direction for chloride ingress. In order to achieve this, the lateral and bottom surfaces of the cubic specimens were painted with epoxy resin in order to ensure that the ingress of chloride ions followed a unidirectional transport from the unpainted surface. Previous to the chloride exposure, the samples were immersed in a $\mathrm{Ca}(\mathrm{OH})_{2}$ solution to restore the moisture loss during the painting process. A pool with a $3 \%$ wt. $\mathrm{NaCl}$ solution was located on the unpainted surface and maintained for 3, 6 and 12 months. A near constant temperature of $20 \pm 2^{\circ} \mathrm{C}$ was maintained throughout the test. Two specimens were manufactured according to binder type, curing age and the exposure time to the chloride source.

Extraction of the core specimens, profile grinding and chloride analysis: At the end of each chloride exposure period, a core specimen with a diameter of $50 \mathrm{~mm}$ and a height of $100 \mathrm{~mm}$ was obtained from the center of each concrete cube, therefore respecting the minimum distance of $10 \mathrm{~mm}$ from the edge of the pool and the painted concrete cube sides, as prescribed in (42). From each core specimen, successive concrete layers were taken for the determination of their chloride contents and the representation of each corresponding chloride profile in order to assess the entrance of these ions into concrete. The first $20 \mathrm{~mm}$ were dry-ground at depth intervals of $2 \mathrm{~mm}$. Then, slices with a thickness of $10 \pm 0.5 \mathrm{~mm}$ were dry-cut with a diamond saw until the total height of the core specimen was completed. Figure 1 shows the arrangement of the specimens during the exposure to chlorides and a sketch of the chloride profile specimens and the layers obtained from them. All the concrete layers were ground in order to also obtain powder size and two powder samples per layer were taken and attacked with nitric acid of $0.5 \mathrm{~mol} / \mathrm{l}$ until all of the chlorides had dissolved in the solution. The total chloride determination was made according to the potentiometric titration method prescribed in (43), using $0.1 \mathrm{M}$ silver nitrate and an automatic 702SM Titrino (Metrohm) titrator controlled with Tinet 2.5 software. The chloride content was expressed as \% by weight of binder (hereinafter bwb). 

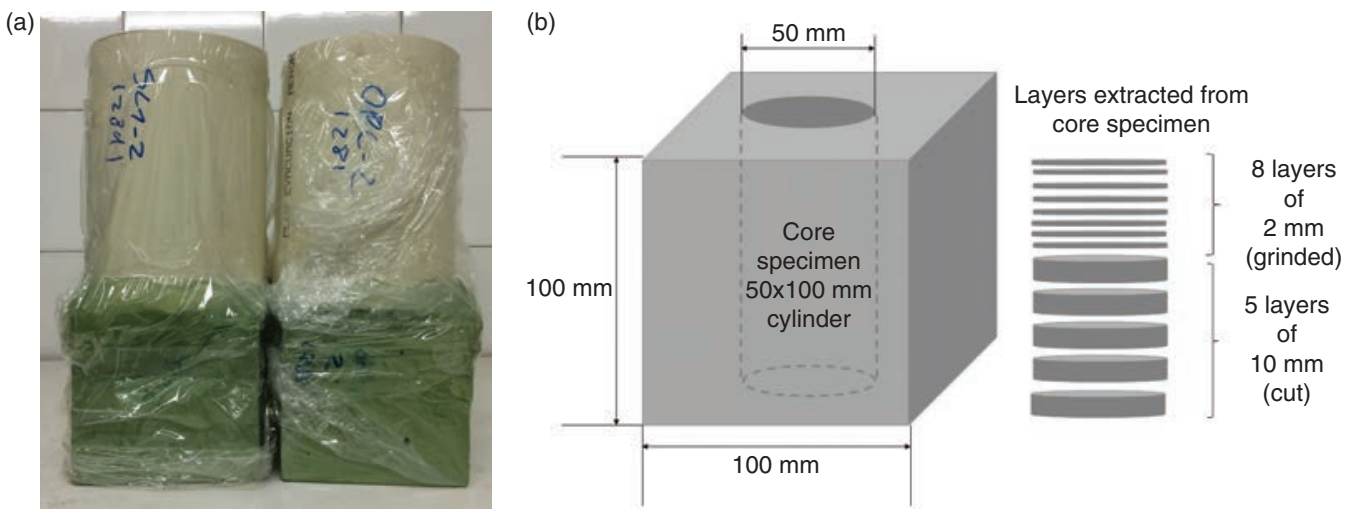

Figure 1. a) Arrangement of the specimens during the chloride exposure period, b) Sketch of the chloride profile specimens and the layers obtained from them.

Determination of the chloride transport parameters: chloride content on the concrete surface $\left(C_{S}\right)$ and non-steady state chloride diffusion coefficient $\left(D_{\text {nat }, \text { nss }}\right):$ The chloride content on the concrete surface $\left(\mathrm{C}_{\mathrm{S}}\right)$ and the non-steady state chloride diffusion coefficient $\left(\mathrm{D}_{\text {nat,nss }}\right)$ were calculated from the non-linear curve fitting the chloride profiles to the solution of Fick's second law of diffusion through minimum squares. The initial chloride content was assumed to be zero. All the layers, from the second layer to the first layer with a concentration lower than $0.015 \%$ by weight of concrete, were considered for the fitting, as prescribed in (42).

\subsection{Pore structure determination}

The porosimetry is also believed to affect the chloride transport through cementitious matrixes. In order to evaluate its effect, mercury intrusion porosimetry tests (MIP) were carried out on mortar specimens. Since the maximum aggregate size of the concretes was $12 \mathrm{~mm}$ and the sample required for the MIP tests was limited to around $1 \mathrm{~cm}^{3}$ ), mortars were manufactured for these tests. The effect of binder type (OPC and SL) and curing time (28 and 90 days) on the porosimetry was evaluated in the same way as with mechanical strength. The porosimetry was not evaluated in samples with hydration ages of longer than 90 days because the changes were not significant between 28 and 90 , which is shown later in the results and demonstrated in (44).

Preparation of samples for the mercury intrusion porosimetry $(M I P)$ : The sampling was taken from the inner part of the mortar specimens. The samples were then vacuum-dried for one week. AutoPore IV 9500 V1.05 equipment was used for the application of the mercury intrusion porosimetry (MIP). The pore size distribution and parameters, such as the total porosity, the tortuosity and the average pore diameter were obtained for further analysis.

\subsection{Mechanical strength characterization}

The compression strength $\left(\mathrm{f}_{\mathrm{c}}\right)$ of the OPC and SL mortars was determined at the curing ages of 28 and 90 days following what is prescribed by EN 1961:2005 (41). Eight specimens were tested to obtain the compression strength of the OPC and SL mortars once the curing period under investigation had been reached.

\section{RESULTS AND DISCUSSION}

\subsection{Effect of the extension of the curing period on mechanical strength and pore structure of ternary blend cementitious systems}

The results of the mechanical tests and some relevant parameters obtained from the porosimetry tests, such as total porosity, mean pore size and tortuosity, are presented in Table 3 . The pore size distributions have been plotted in Figure 2.

Firstly, Table 3 indicates that SL mortar always shows lower porosity than OPC mortar, regardless of the curing time applied. The reason for the lower porosity of SL mortar could be related to several factors associated with BFS and LF:

- The introduction of fine particles, such as BFS and LF, makes a denser cementitious matrix, which is noticeable from the beginning.

- BFS favors the formation of more C-S-H gel than OPC at advanced curing ages (26, 45-47) and therefore, a higher densification of the cement paste is expected. Furthermore, the refinement of the pore structure in SL mortar could also be a consequence of the LF addition, which stabilizes monocarbonate and indirectly the formation of ettringite. This leads to an increase in the amount of hydrated phases and a decrease in porosity, as suggested in (48, 49). Additionally, a synergic effect exists in the 
The influence of curing and aging on chloride transport through ternary blended cement concrete $\bullet 5$

TABLE 3. Mechanical strength and porosimetry of OPC and SL mortar specimens after 28 and 90 days of curing

\begin{tabular}{lccccc}
\hline Binder & $\begin{array}{c}\text { Curing time } \\
(\mathbf{d a y s})\end{array}$ & $\begin{array}{c}\text { Compression } \\
\text { strength (MPa) }\end{array}$ & $\begin{array}{c}\text { Total } \\
\text { porosity }(\boldsymbol{\%})\end{array}$ & $\begin{array}{c}\text { Average pore } \\
\text { diameter }(\boldsymbol{\mu m})\end{array}$ & Tortuosity \\
\hline OPC & 28 & $51.4 \pm 2.5$ & 16.8 & 0.09 & 50.5 \\
& 90 & $55.3 \pm 3.7$ & 15.9 & 0.07 & 60.3 \\
SL & 28 & $47.2 \pm 2.9$ & 12.9 & 0.04 & 36.4 \\
& 90 & $56.3 \pm 1.0$ & 11.0 & 0.04 & 11.1 \\
\hline
\end{tabular}
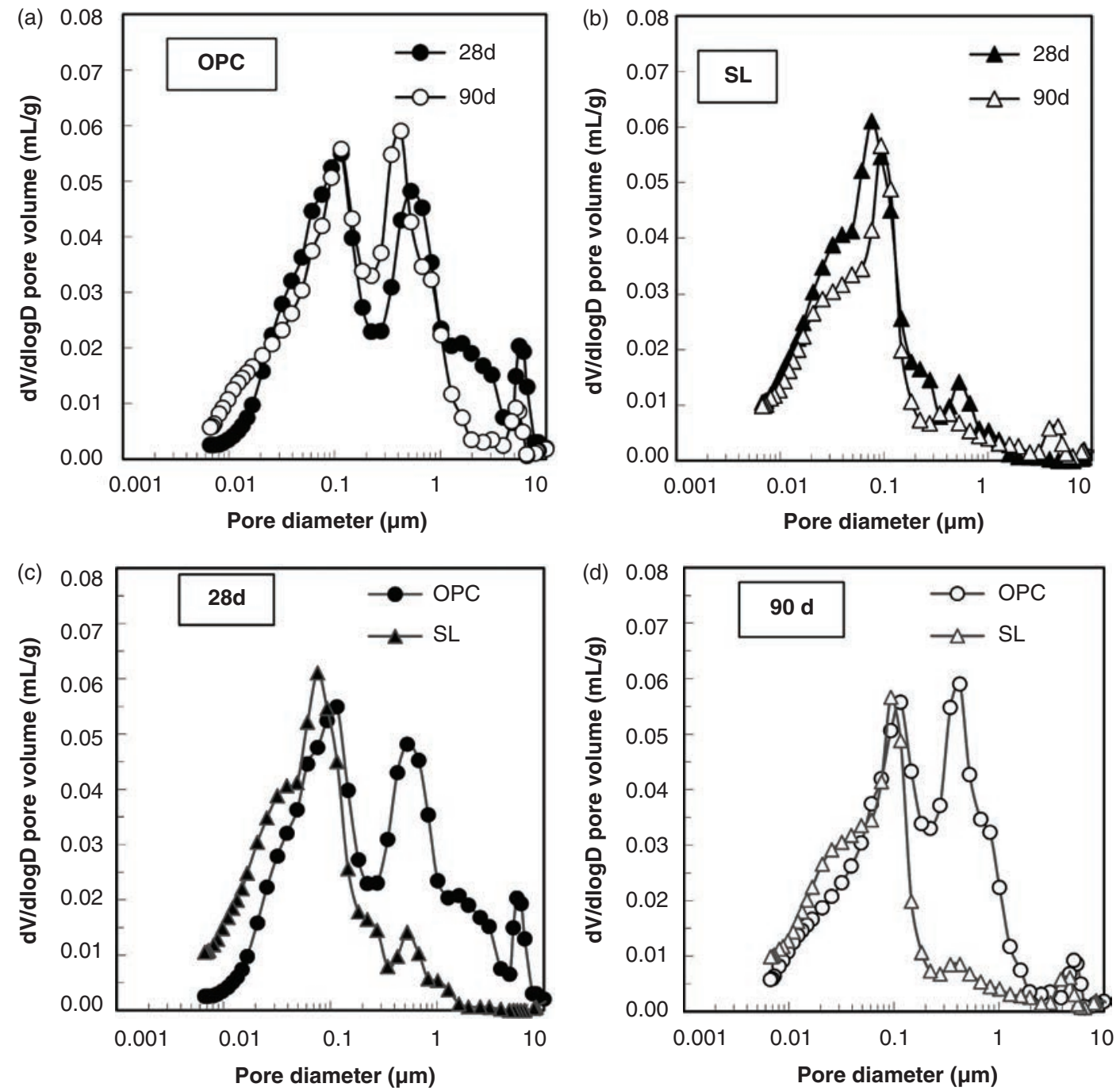

FIGURE 2. Pore size distribution of mortars: a) OPC after 28 and 90 days of curing; b) SL after 28 and 90 days of curing; c) OPC and SL after 28 days of curing; d) OPC and SL after 90 days of curing

presence of these two SCM's because LF can intensify the hydration of BFS, as described in (50).

Furthermore, similar porosimetry was observed in the specimens cured for 90 days to those cured for 28 days, regardless of the type of binder used
(Table 3). These results reveal that the extension of the curing period from 28 to 90 days slightly changed the porosity structure, even when the binder with SCM's was used, although the total porosity or amount of pores diminished.

With regard to the mechanical performance of mortars and its relationship with pore structure, 
Table 3 shows that SL mortar attained lower compression strength than OPC mortar after 28 days of curing but this is higher after 90 days. The relationship between total porosity and compression strength can be analyzed from Figure 3.

Figure 3 shows that although porosity diminishes and compression strength increases with curing time, regardless of the binder type, two areas of compression strength-porosity can be differentiated, depending on the binder employed, characterized by similar compression strength values at 90 days for both mortars but lower porosity values for the blended mortar.

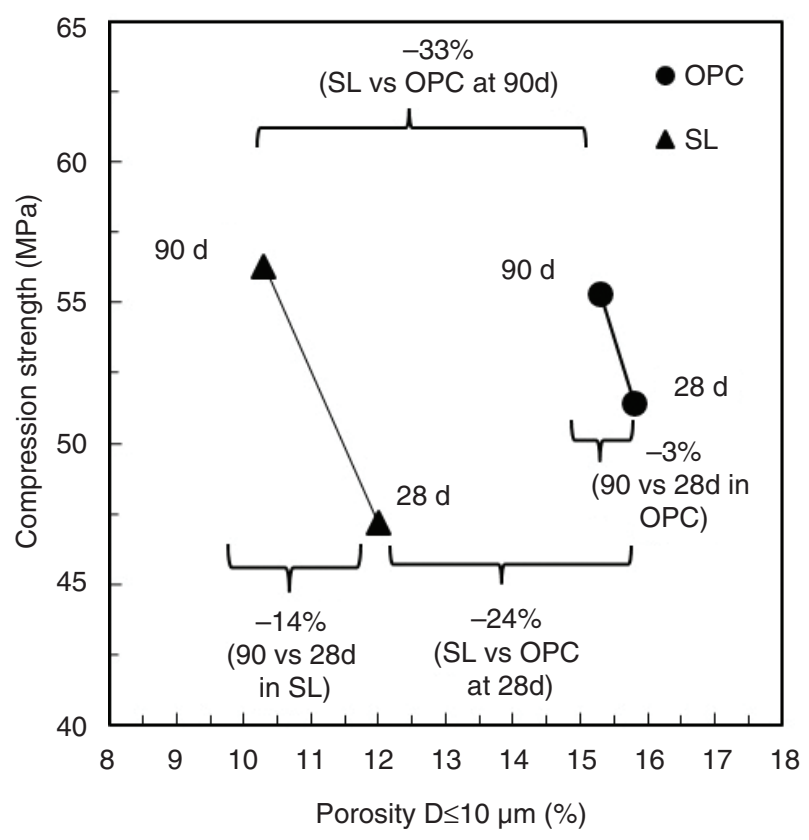

FIGURE 3. Relationship between total porosity (neglecting porosity associated to pore diameters higher than $10 \mu \mathrm{m}$ ) and compression strength for OPC and SL mortar
Furthermore, Figure 3 highlights greater variations occurred in the parameters studied as a consequence of the extension of the curing period when the SL cement was used than in the case of OPC, $14 \%$ versus $3 \%$ in the case of porosity and $33 \%$ versus $24 \%$ in the case of compression strength from 28 to 90 hydration days. These greater variations mean that the curing extension from 28 to 90 days is more effective for pore structure change when the cement with SCM's was used, which justifies the extension of the curing period from 28 to 90 days, something that some construction standards are considering as a requirement for the determination of the mechanical strength in concretes containing SCM's.

\subsection{Results on the chloride transport in ternary blended concretes}

The exposure of the concrete specimens to the unidirectional transport of chlorides allowed chloride profiles to be obtained, such as those shown in Figure 4 for the specimens exposed to the chloride source for 3 months after being cured for 28 (a) and 90 days (b).

The chloride profiles shown in Figure 4 have very similar appearance, regardless of the binder type, which makes it difficult to extract any information from them about the influence of the binder type on the transport of these ions though the concretes. Similar difficulties are found when the effect of curing time and chloride exposure time is analyzed from the chloride profiles, meaning that in order to clarify the effect of these two factors, the chloride diffusion coefficient at non-steady state $\left(D_{\text {nat,nss }}\right)$ and the surface chloride content $\left(C_{S}\right)$ of each specimen was obtained from the corresponding chloride profile. Table 4 shows the average values and the standard deviations of these two parameters per condition tested.
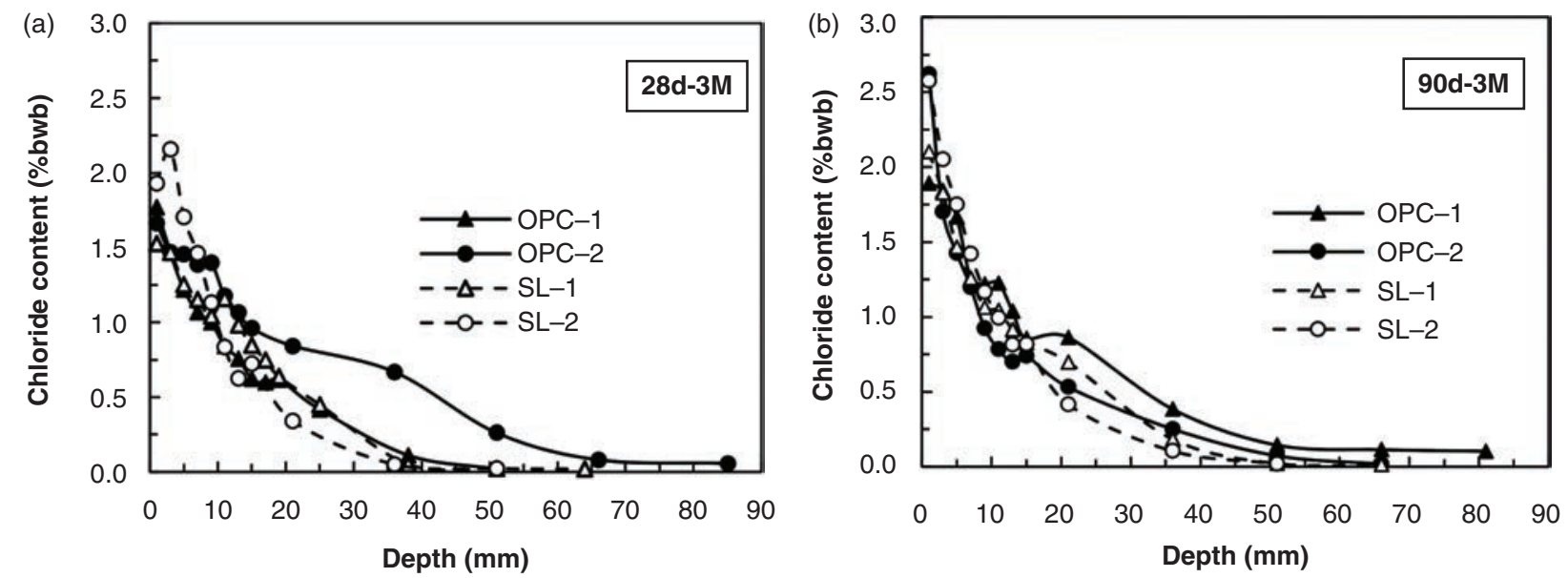

FIGURE 4. Chloride profiles in OPC and SL concrete after curing and 3 month-exposure to chlorides: a) 28-day curing period, b) 90 -day curing period 
First, in Table 4 the variability of results between the two specimens for a matching condition can be highlighted. This reflects the importance of testing several specimens for a better interpretation of the results, as standards suggest [42].

The average values of $D_{\text {nat,nss }}$ and $C_{S}$ have been plotted in Figure 5 for a better clarification of the results and a clearer discussion of the effect of the addition of BFS and LF, the extension of the curing period, and exposure time to chlorides on the concrete resistance to natural diffusion chloride penetration.

\subsubsection{The effect of binder type on chloride transport through concrete}

As can be observed in Figure 5.a, the values of the chloride diffusion coefficient $\mathrm{D}_{\text {nat,nss }}$ obtained in the concrete with SCM's were mostly lower than those found in OPC concrete, which, in general, adopted values that were at least twice as low. The lower $\mathrm{D}_{\mathrm{nss}}$ of SL concrete, associated with higher resistance to chloride penetration, might be attributed to several factors. One is the more refined pore structure of the blended concrete during the

TABLE 4. Non-steady state chloride diffusion coefficients and surface chloride contents determined from natural penetration tests

\begin{tabular}{|c|c|c|c|c|}
\hline Concrete & Curing time (d) & Exposure time (months) & $\begin{array}{c}D_{\text {nat,nss }} \\
\left(\cdot 10^{-12} \mathrm{~m}^{2} / \mathrm{s}\right) \\
\end{array}$ & $\mathrm{C}_{\mathrm{s}}(\% \mathrm{bwb})$ \\
\hline \multirow[t]{6}{*}{$\mathrm{OPC}$} & 28 & 3 & $57.6 \pm 44.1$ & $1.56 \pm 0.03$ \\
\hline & & 6 & $63.0 \pm 0.3$ & $1.88 \pm 0.24$ \\
\hline & & 12 & $50.4 \pm 3.9$ & $1.71 \pm 0.03$ \\
\hline & 90 & 3 & $30.1 \pm 12.0$ & $1.82 \pm 0.01$ \\
\hline & & 6 & $25.6 \pm 19.0$ & $1.95 \pm 1.26$ \\
\hline & & 12 & $79.0 \pm 24.8$ & $1.68 \pm 0.47$ \\
\hline \multirow[t]{6}{*}{ SL } & 28 & 3 & $21.9 \pm 12.4$ & $2.08 \pm 0.69$ \\
\hline & & 6 & $8.9 \pm 1.1$ & $2.26 \pm 0.40$ \\
\hline & & 12 & $10.9 \pm 0.1$ & $2.28 \pm 0.30$ \\
\hline & 90 & 3 & $19.8 \pm 6.3$ & $2.10 \pm 0.36$ \\
\hline & & 6 & $11.2 \pm 4.7$ & $2.84 \pm 0.20$ \\
\hline & & 12 & $10.5 \pm 1.1$ & $2.38 \pm 0.15$ \\
\hline
\end{tabular}
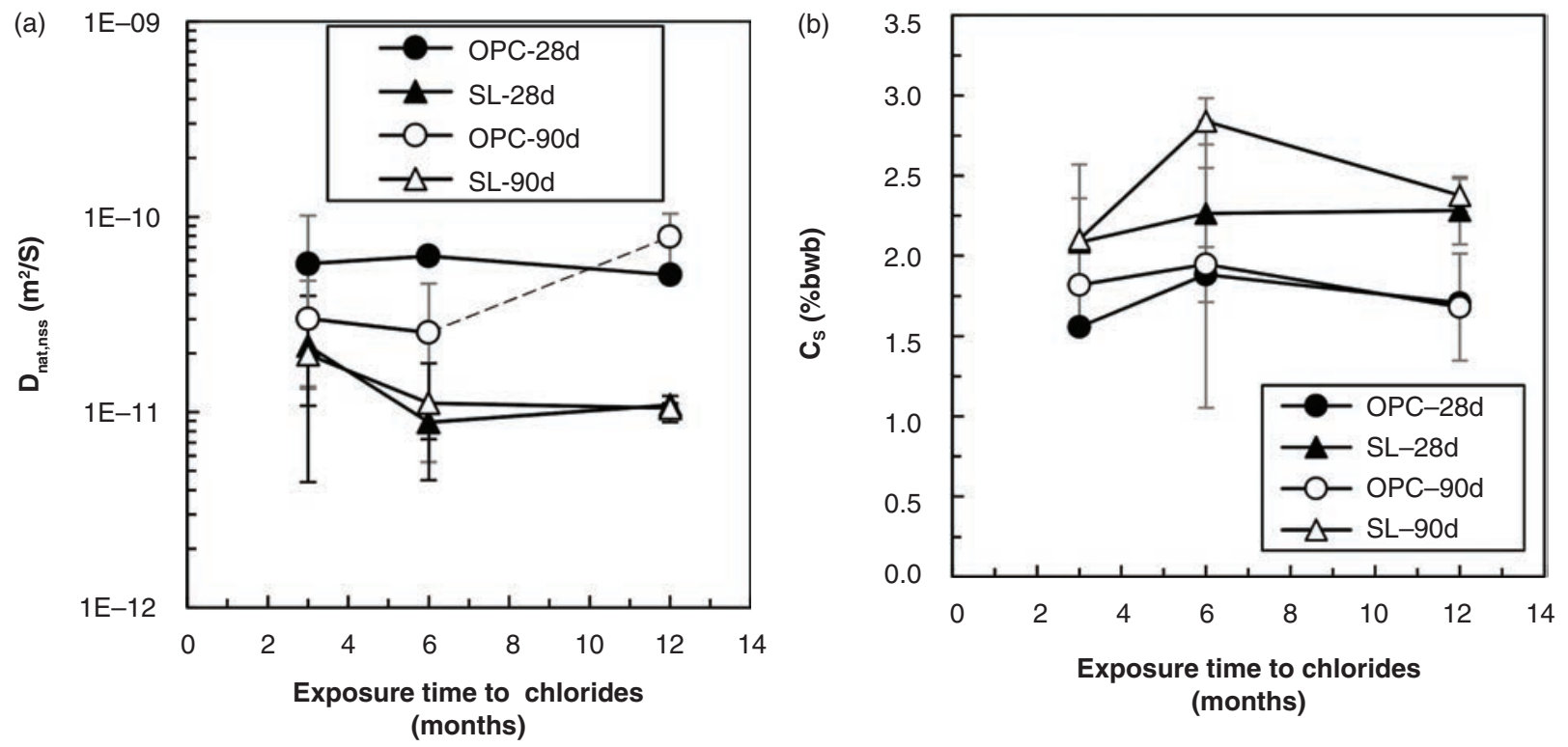

FIGURE 5. Concrete resistance to chloride penetration: a) Average values of chloride diffusion coefficients, b) Average values of surface chloride content 
exposure time, as a continuation of that observed at the end of curing (see Figure 2 and Table 3). Additionally, the gel of SL cement should have a lower C/S ratio and more Al (19-21) and should be at a higher magnitude (22-25), which might also cause the decrease in the penetration rate of these ions into the concretes containing this SCM. Furthermore, the slower entrance of chlorides into SL concrete is related to the composition of the BFS, which contributes to hydrated phases that are richer in $\mathrm{Al}_{2} \mathrm{O}_{3}$, which enhances its ability to bind chlorides (22-25) compared to OPC used in this study, with low aluminate content and therefore, lower $\mathrm{Cl}$ binding capacity.

Figure 6 shows the relationship between chloride transport and porosity through the representation of $\mathrm{D}_{\text {nat,nss }}$ values obtained after the three exposure periods tested and the initial total porosity values.

Figure 6.a confirms that the lower porosity of SL mortar when compared to OPC mortar leads to lower chloride diffusion coefficients in concretes. However, it is important to highlight that while mortars with porosities between around 11 and $16 \%$ have attained similar $D_{\text {nat,nss }}$ values (around $10-20 \cdot 10^{-12} \mathrm{~m}^{2} / \mathrm{s}$ ), mortars with total porosities of higher than $16 \%$ have attained much higher $\mathrm{D}_{\text {nat,nss }}$ values (around $50-70 \cdot 10^{-12} \mathrm{~m}^{2} / \mathrm{s}$ ). These results suggest an indirect relationship between total porosity and the chloride diffusion coefficient, but might also indicate the existence of a porosity threshold above which chloride transport through concrete increases exponentially. Although further study is needed on the concrete correlation of porosity and chloride transport, and the overlap with the chloride binding associated with binder type.

Regarding the surface chloride content $\mathrm{C}_{\mathrm{S}}$ (see Figure 5.b), higher values were attained in SL concrete than in the case of OPC concrete, which is in accordance with the higher binding capacity of the SL concrete skin than that of OPC concrete, something that also controls the chloride transport into concrete and the determination of the $\mathrm{D}_{\text {nat,nss }}$ values (Figure 5.a).

\subsubsection{The effect of the length of the curing period on chloride diffusion through blended cement concretes}

As can be observed in Figure 5 for both OPC and SL concrete, similar values of $D_{\text {nat,nss }}$ were found at a certain exposure time to the chloride source , regardless of the time for which the specimens were cured (28 and 90 days) (note that not only average values but also deviation values have to be considered and that higher differences apparently shown by OPC concrete are a consequence of the scale of the Y-axis). These results prove that the extension of the curing period from 28 to 90 days is not a parameter which has a great influence and is not an effective measure to assess the transport of chlorides in blended concretes. The extension of the curing period cannot be justified for blended concretes as it is for the evolution of mechanical strength, as a consequence of the SCM hydration progression and the increase in the amount of hydrated phases such as C-S-H [44]. Besides the extension of curing does not modify the binding capacity of the concrete, meaning that hydration progresses during the $\mathrm{Cl}$ transport tests.

However, while $\mathrm{D}_{\text {nat,nss }}$ was slightly modified by the extension of the curing period from 28 to 90 days, the compression strength varied considerably with the extension of the curing period, at least in the case of the SL concrete. This result could be due to the fact that the hydration state of the specimens from which the chloride diffusion coefficients were
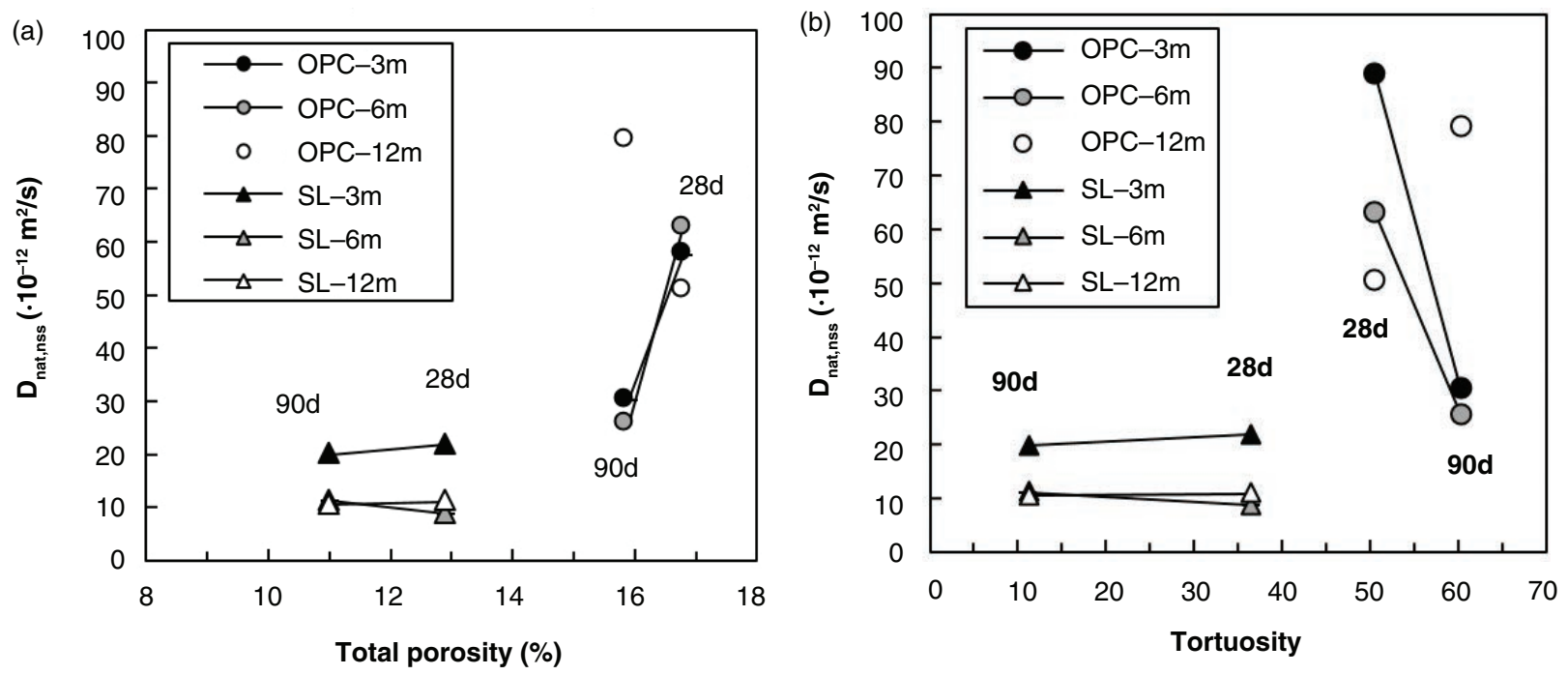

FIGURE 6. Relationship between chloride diffusion coefficient and porosimetry: a) $D_{\text {nat,nss }}$-Total porosity, , b) $D_{\text {nat,nss }}$-Tortuosity 
calculated was more similar than that of the specimens used to determine the compression strength.

As can be observed in the $D_{\text {nat,nss }}$ values (see Figure 5.a), no remarkable differences were found in the $\mathrm{C}_{\mathrm{S}}$ values attained in both OPC and SL concrete as a consequence of the extension of the curing period (see Figure 5.b). These results indicate that the penetration of chlorides into the two concretes analyzed is not influenced by the curing time extension from 28 to 90 days.

\subsubsection{Effect of concrete aging due to chloride exposure on chloride penetration}

After the development of the final microstructure of the concrete, an aging process starts, which also consists of a change of microstructure and properties and characteristics of the concrete. The aging phenomenon has consequences on chloride transport into concrete and Figure 5 shows these effects for the $\mathrm{OPC}$ and SL concrete analyzed in this research.

As can be observed in Figure 5.b, similar values of $\mathrm{C}_{\mathrm{S}}$ were obtained after the three periods of exposure analyzed. A possible explanation for the unclear effect of exposure time on the chloride content accumulated on the concrete surface (skin) might be that $\mathrm{C}_{\mathrm{S}}$ values oscillate around the saturation content of chlorides, because although several years could be needed to reach the saturation content due to phenomena of cyclic binding/leaching (51), values which are close to the saturation value are reached in a short time due to the exponential character of the saturation curve.

Figure 5.a also shows that the chloride diffusion coefficients tend to stabilize with exposure and decrease with time, although the effect is clearer in the case of SL concrete, with a diminution of the $D_{\text {nat.nss }}$ after the first 6 months of exposure, indicating that SL concrete is affected by the aging effect. These results agree with those found by other authors on the influence of aging on chloride transport (5254), with major reductions in the chloride diffusion coefficients due to the longer hydration processes of cements with SCM's and also the $\mathrm{Cl}$ binding evolution and penetration depths until a certain stabilization is reached. Furthermore, all these results prove the importance of the exposure time to chlorides in the determination of the chloride diffusion coefficient in blended cement concretes.

\section{CONCLUSIONS}

The following conclusions have been drawn from the results obtained in the materials employed in this research:

- The partial substitution of OPC by BFS and $\mathrm{LF}$ in the proportions specified in this research reduces the chloride diffusion in concrete by half.
- The extension of the curing time (from 28 to 90 days) does not significantly affect the transport of chlorides, even in concretes with SCM's, as used in this study with 30\% BFS and 6\% LF.

- The chloride transport decreases with the exposure time to the chloride source, especially when SCM's with a high binding capacity are used.

- The exposure time to the chloride source (3, 6 and 12 months) is a relevant parameter to achieve stable diffusion coefficients. Chloride transport test lengths of at least 6 months are required from this study.

\section{ACKNOWLEDGEMENTS}

The authors would like to thank the Ministerio de Economía y Competitividad for financing the IMCORPRO BIA2011-22670 research project and especially Javier Luna for the BES-2012-061300 funds. The authors would also like to thank the suppliers of the raw materials. In addition, the authors would like to thank the technician Virtudes FlorLaguna for her contribution to the acid-soluble chloride analysis.

\section{REFERENCES}

1. Meira, G.R.; Padaratz, I.J.; Alonso, C.; Andrade, C. (2003) Effect of distance from sea on chloride aggressivenes in concrete structures in brazilian coastal site. Mater. Construcc. 53, 179-188. https://doi.org/10.3989/mc.2003. v53.i271-272.302.

2. Browne, R. (1982) Design prediction of the life for reinforced concrete in marine and other chloride environments. Durab. Build. Mater. 1, 113-125.

3. Funahashi, M. (1990) Predicting corrosion free service life of a concrete structure in a chloride environment. $A C I$ Mater. J. 87, 581-587.

4. Maage, M.; Helland, S.; Carlsen, J. (1995) Practical nonsteady chloride transport as a part of a model for predicting the initiation period. In: Nilsson LO, Ollivier J, editors. RILEM Int. Work. Chloride Penetration into Concr., p. 398-406.

5. EN 1992-1-1:2004. Eurocode 2: Design of concrete structures Part 1: General rules and rules for buildings, Brussels, Belgium: CEN (European Committee for Standardization); 2004.

6. Menéndez, G.; Bonavetti, V.L.; Irassar, E.F. (2007) Ternary blend cements concrete. Part II: Transport mechanism. Mater. Construcc. 57, 31-43. https://doi.org/10.3989/mc. 2007.v57.i285.37.

7. Álava, H.E.; Tsangour, E.; Belie, N. de; Schutter, G. de (2016) Chloride interaction with concretes subjected to a permanent splitting tensile stress level of $65 \%$. Constr. Build. Mater. 127, 527-538. https://doi.org/10.1016/j. conbuildmat.2016.10.009.

8. Mohammed, T.U.; Yamaji, T.; Hamada, H. (2002) Chloride diffusion, microstructure and mineralory of concrete after 15 years of exposure in tidal environment. ACI Mater. J. 99, 256-263.

9. Ryan, P.C.; O'Connor, A. (2016) Comparing the durability of self-compacting concretes and conventionally vibrated concretes in chloride rich environments. Constr. Build. Mater. 120, 504-513. https://doi.org/10.1016/j. conbuildmat.2016.04.089.

10. Bamforth, P.B.; Price, W.F. (1993) Factors influencing chloride ingress into marine structures. In: Dhir RK, Jones MR, editors. Infrastructure, Res. new Appl., Dundee (Scotland): Spon; p. 1105-18. 
11. Bamforth, P.B. (1999) The derivation of input data for modeling chloride ingress from eight-years. Mag. Concr. Res. 51, 87-96. https://doi.org/10.1680/macr.1999.51.2.87.

12. Bentz, E.C.; Evans, C.M.; Thomas, M.D.A. (1996) Chloride diffusion modelling for marine exposed concretes. In: Page CL, Bamforth PB, Figg JW, editors. Corros. Reinf. Concr. Constr., Cambridge (UK): The Royal Society of Chemistry Publication; p. 136-45.

13. Paiva, H.; Velosa, A.; Cachimb, P.; Ferreira, V.M. (2016) Effect of pozzolans with different physical and chemical characteristics on concrete properties. Mater. Constr. 66, 1-12. https://doi.org/10.3989/mc.2016.01815.

14. Al-Swaidani, A.M. (2017) Production of more durable and sustainable concretes using volcanic scoria as cement replacement. Mater. Construcc. 67. https://doi.org/10.3989/ mc.2017.00716.

15. Mangat, P.S.; Molloy, B.T. (1991) Influence of PFA, slag and microsilica on chloride induced corrosion of reinforcement in concrete. Cem. Concr. Res. 21, 819-834. https:// doi.org/10.1016/0008-8846(91)90177-J.

16. Yoo, S.-W.; Kwon, S.-J. (2016) Effects of cold joint and loading conditions on chloride diffusion in concrete containing GGBFS. Constr. Build. Mater.115, 247-255. https://doi.org/10.1016/j.conbuildmat.2016.04.010.

17. Lee, B.; Kim, G.; Nam, J.; Cho, B.; Hama, Y.; Kim, R. (2016) Compressive strength, resistance to chloride-ion penetration and freezing/thawing of slag-replaced concrete and cementless slag concrete containing desulfurization slag activator. Constr. Build. Mater. 128, 341-348. https:// doi.org/10.1016/j.conbuildmat.2016.10.075.

18. ACI Committee 233. (1995) Ground Granulated blastfurnace slag as a cementitious constituent in concrete. $A C I$ Mater. J. 92, 1-18.

19. Bijen, J. (1996) Benefits of slag and fly ash. Constr. Build. Mater. 10, 309-314. https://doi.org/10.1016/0950-0618(95)00014-3.

20. Geiseler, J.; Kollo, H.; Lang, E. (1995) Influence of blast furnace cements on durability of concrete structures. $A C I$ Mater. J. 92, 252-257.

21. Lauch, K.S.; Dieryck, V. (2016) Durability of concrete made with ternary cements containing slag or fly ash and limestone filler. Int RILEM Conf Mater Syst Struct Civ Eng Conf Segm Concr with SCM's.

22. Kocaba, V.; Gallucci, E.; Scrivener, K.L. (2012) Methods for determination of degree of reaction of slag in blended cement pastes. Cem. Concr. Res. 42, 511-525. https://doi. org/10.1016/j.cemconres.2011.11.010

23. Menéndez, G.; Bonavetti, V.; Irassar, E.F. (2003) Strength development of ternary blended cement with limestone filler and blast-furnace slag. Cem. Concr. Compos. 25, 61-67. https://doi.org/10.1016/S0958-9465(01)00056-7.

24. Ortega, J.M.; Sánchez, I.; Climent, M.Á. (2013) Influence of different curing conditions on the pore structure and the early age properties of mortars with fly ash and blastfurnace slag. Mater. Construcc. 63, 219-234. https://doi org/10.3989/mc.2012.06111.

25. Al-Assadia, G.; Casatib, M.J.; Gálvez, J.C.; Fernández, J.; Aparicio, S. (2015) The influence of the curing conditions of concrete on durability after freeze-thaw accelerated testing. Mater. Construcc. 65, 1-17. https://doi.org/10.3989/mc.2015.06514

26. Bamforth PB. Enhancing reinforced concrete durability. Guidance on selecting measures for minimizing the risk of corrosion of reinforcement in concrete. Technical Report 61. The Concrete Society. Camberley: 2004.

27. Nilsson, L.O.; Carcassès, M. (2002) Models for chloride ingress into concrete-a critical analysis. Report on task 4.1, EU project "ChlorTest" G6RD-CT-2002-0085, Building Materials, Lund Institute of Technology. Lund (Sweden).

28. Vedalakshmi, R.; Saraswathy, V.; Song, H.W.; Palaniswamy, N (2009) Determination of diffusion coefficient of chloride in concrete using Warburg diffusion coefficient. Corros. Sci. 51, 1299-1307. https://doi.org/10.1016/j.corsci.2009.03.017.

29. Attari, A.; McNally, C.; Richardson, M.G. (2016) A probabilistic assessment of the influence of age factor on the service life of concretes with limestone cement/GGBS binders. Constr. Build. Mater. 111, 488-494. https://doi. org/10.1016/j.conbuildmat.2016.02.113.
30. Teng, S.; Lim, T.Y.D.; Sabet Divsholi, B. (2013) Durability and mechanical properties of high strength concrete incorporating ultra fine ground granulated blast-furnace slag. Constr. Build. Mater. 40, 875-881. https://doi.org/10.1016/j. conbuildmat.2012.11.052.

31. Ben Fraj, A.; Bonnet, S.; Khelidj, A. (2012) New approach for coupled chloride/moisture transport in non-saturated concrete with and without slag. Constr. Build. Mater. 35, 761771. https://doi.org/10.1016/j.conbuildmat.2012.04.106.

32. Shin, H.-O.; Yang, J.-M.; Yoon, Y.-S.; Mitchell, D. (2016) Mix design of concrete for prestressed concrete sleepers using blast furnace slag and steel fibers. Cem. Concr. Compos. 74, 39-53. https://doi.org/10.1016/j.cemconcomp.2016.08.007.

33. EN 12390-2:2015. (2015) Testing hardened concrete. Part 2: Making and curing specimens for strength tests, CEN (European Committee for Standardization).

34. EN 196-1:2005. (2005) Methods of testing cement. Part 1: Determination of strength, Brussels (Belgium): CEN (European Committee for Standardization); p. 36.

35. EN 12390-11:2015. (2015) Testing hardened concrete. Part 11: Determination of the chloride resistance of concrete, unidirectional diffusion, CEN (European Committee for Standardization)

36. EN 14629:2007. (2007) Products and systems for the protection and repair of concrete structures. Test methods. Determination of chloride content in hardened concrete, CEN (European Committee for Standardization).

37. Carrasco, M.F.; Menéndez, G.; Bonavetti, V.; Irassar, E.F. (2005) Strength optimization of tailor-made cement with limestone filler and blast furnace slag. Cem. Concr. Res. $35,1324-1331$. https://doi.org/10.1016/j.cemconres.2004. 09.023 .

38. Manhoman, D.; Metha, P.K. (1981) Influence of pozzolanic, slag and chemical admixtures on pore size distribution and permeability of hardened cement pastes. Cem. Concr. Aggregates 3, 63-67. https://doi.org/10.1520/CCA10203J.

39. Ortega, J.M.; Ferrándiz, V.; Antón, C.; Climent, M.Ä.; Sánchez, I. (2009) Influence of curing conditions on the mechanical properties and durability of cement mortars. In: Mammoli AA, Brebbia CA, editors. Mater. Charact. IV Comput. methods Exp., Ashurst (UK): WitPress; p. 381-91. https://doi.org/10.2495/MC090361.

40. Schiessl, P.; Wiends, U. (1995) Rapid determination of chloride diffusivity in concrete with blending agents. In: Nilsson LO, Ollivie JP, editors. RILEM Int. Work. Chloride Penetration into Concr., RILEM Publications SARL; p. 115-25.

41. Lothenbach, B.; Le Saout, G.; Gallucci, E.; Scrivener, K. (2008) Influence of limestone on the hydration of Portland cements. Cem. Concr. Res. 38, 848-860. https:// doi.org/10.1016/j.cemconres.2008.01.002.

42. Fernández Pérez, Á.; García Calvo, J.L.; Alonso Alonso, M.C. (2018) Ordinary Portland Cement composition for the optimization of the synergies of supplementary cementitious materials of ternary binders in hydration processes. Cem. Concr. Compos. 89, 238-250. https://doi. org/10.1016/j.cemconcomp.2017.12.016.

43. Adu-Amankwah, S.; Zajac, M.; Stabler, C.; Lothenbach, B.; Black, L. (2017) Influence of limestone on the hydration of ternary slag cements. Cem. Concr. Res. 100, 96-109. https:// doi.org/10.1016/j.cemconres.2017.05.013.

44. Lothenbach, B.; Scrivener, K.; Hooton, R. (2011) Supplementary cementitious materials. Cem. Concr. Res. 41, 1244-1256. https://doi.org/10.1016/j.cemconres.2010. 12.001 .

45. Rasheeduzzafar, Hussain, E. (1991) Effect of microsilica and blast furnace slag on pore solution and alkali-silica reaction. Cem. Concr. Compos. 12, 219-225. https://doi. org/10.1016/0958-9465(91)90023-B.

46. Glasser,F.P.; Luke,K.; Angus, M.(1988)Modification of cement pore fluid compositions by pozzolanic additives. Cem. Concr. Res. 18, 165-78. https://doi.org/10.1016/0008-8846(88)90001-4.

47. Leng, F.; Feng, N.; Lu X. (2000) An experimental study on the properties of resistance to diffusion of chloride ions of fly ash and blast furnace slag concrete. 
Cem. Concr. Res. 30, 989-992. https://doi.org/10.1016/ S0008-8846(00)00250-7.

48. Detwiler, R.J.; Fapohunda, C.A.; Natale, J. (1994) Use of supplementary cementing materials to increase the resistance to chloride ion penetration of concretes cured at elevated temperatures. ACI Mater. J. 91, 63-66.

49. Moon, H.Y.; Kim, H.S.; Choi, D.S. (2006) Relationship between average pore diameter and chloride diffusivity in various concretes. Constr. Build. Mater. 20, 725-732. https://doi.org/10.1016/j.conbuildmat.2005.02.005.

50. Song, H.W.; Saraswathy, V. (2006) Studies on the corrosion resistance of reinforced steel in concrete with ground granulated blast-furnace slag-An overview. J. Hazard Mater. 138, 226-233. https://doi.org/10.1016/j.jhazmat. 2006.07.022.
51. Polder, R.B.; Rooij, M.R. de (2005) Durability of marine concrete structures - Field investigations and modelling. Heron 50, 133-154.

52. Nokken, M.; Boddy, A.; Hooton, R.D.; Thomas, M.D.A (2006). Time dependent diffusion in concrete - three laboratory studies. Cem. Concr. Res. 36, 200-207. https://doi. org/10.1016/j.cemconres.2004.03.030.

53. Stanish, K.; Thomas, M. (2003) The use of bulk diffusion tests to establish time-dependent concrete chloride diffusion coefficients 33, 55-62. https://doi.org/10.1016/ S0008-8846(02)00925-0.

54. Thomas, M.D.A.; Bamforth, P.B. (1999) Modelling chloride diffusion in concrete. Effects of fly ash and slag, Cem. Concr. Res. 29 [4], 487-495. https://doi.org/10.1016/ S0008-8846(98)00192-6. 